Journal of Physical Science, Vol. 27(2), 41-54, 2016

\title{
Enhanced Band Gap Energy and Electrochromic Behaviour of Selenium Incorporated Copper Thin Film
}

\author{
Peter Joseph, Karpagavinayagam Petchimuthu and Vedhi Chinnapiyan ${ }^{*}$ \\ Department of Chemistry, V. O. Chidambaram College, \\ Thoothukudi 628008, Tamilnadu, India \\ *Corresponding author: cvedhi@rediffmail.com; cvedhi23@gmail.com
}

Published online: 25 August 2016

To cite this article: Joseph, P., Petchimuthu, K. \& Chinnapiyan, V. (2016). Enhanced band gap energy and electrochromic behaviour of selenium incorporated copper thin film. J. Phys. Sci., 27(2), 41-54, DOI: 10.21315/jps2016.27.2.4

To link to this article: http://dx.doi.org/10.21315/jps2016.27.2.4

\begin{abstract}
Selenium incorporated copper (CuSe) thin films are deposited on indium tin oxide (ITO) substrate by cyclic voltammogram of $5.0 \mathrm{ml}$ of $0.1 \mathrm{M} \mathrm{CuSO}_{4}$ and $2 \mathrm{ml}$ of 0.05 $\mathrm{M}$ selenium dioxide at potential range from $-0.8 \mathrm{~V}$ to $0.7 \mathrm{~V} v \mathrm{~s} . \mathrm{Ag} / \mathrm{AgCl}$ in $\mathrm{pH} \mathrm{1.0.} \mathrm{The}$ adherent nature, electroactivity and stability of the CuSe thin film were found to be good. The transmittance and absorption of thin films was analysed through UV-Vis spectra. An energy gap of $1.78 \mathrm{eV}$ is obtained for CuSe thin films by extrapolating the linear portion of the curves hv versus (ahv) ${ }^{2}$. X-ray diffraction patterns revealed that the deposited films possess cubic structure with lattice constant (a) value 80.892A. Surface morphology of thin film shows uniform granular mixed texture-like structure. The sizes of the grains are found to be in the range between $53.33 \mathrm{~nm}$ and $93.33 \mathrm{~nm}$. The film composition was investigated using an energy dispersive X-ray (EDX) micro analytic unit attached with scanning electron microscope. The in-situ spectroelectrochemical behaviour of CuSe thin film at various applied potentials was observed in $0.1 \mathrm{M} \mathrm{H}_{2} \mathrm{SO}_{4}$. CuSe thin film exhibits dual colour chromic behaviour from contrast red colour to contrast yellows colour. The electrochromic device shows good optical contrast, coloration efficiency, response time and stability.
\end{abstract}

Keywords: Electrodeposition, thin film, Band gap energy, electrochromic device, selenium

\section{INTRODUCTION}

Copper selenide (CuSe) is a direct band gap p-type semiconductor with an energy gap value in the range between 2.1 and $2.7 \mathrm{eV}$, making them interesting for solar energy conversion. ${ }^{1-5}$ Copper selenide has many structural phases such as $\alpha$ $\mathrm{Cu}_{2} \mathrm{Se}, \mathrm{Cu}_{3} \mathrm{Se}_{2}, \mathrm{CuSe}$ and $\mathrm{CuSe}_{2}$ in stoichiometric form and $\mathrm{Cu}_{2-\mathrm{x}} \mathrm{Se}$ phase in nonstoichiometric layer form. ${ }^{6-9}$ Thin films of CuSe are normally crystallised in 
hexagonal structure and orthorhombic structure. Numerous techniques have been used to obtain $\mathrm{CuSe}$ thin films viz., thermal evaporation, ${ }^{10}$ vacuum evaporation, ${ }^{11}$ solution growth technique, ${ }^{6-12}$ chemical bath deposition, ${ }^{13-19}$ colloidal hot injection method, ${ }^{20}$ vapour deposition, ${ }^{21}$ and electrophoretic deposition. ${ }^{22}$ Among them, electrodeposition technique provides many advantages over vacuum and other processes, such as low temperature growth, control of film thickness and morphology, potentially low capital $\operatorname{cost}^{1,23}$ and others. The $\mathrm{Cu}_{2-\mathrm{x}} \mathrm{Se}$ films are typically p-type, highly conductive, semitransparent semiconductors with a band gap varying between 1.1 and $1.4 \mathrm{eV}$, suitable for solar energy conversion and, as semitransparent layers, in high speed detectors working within the visible range. ${ }^{24,25} \mathrm{Cu}_{2} \mathrm{Se}$ is used as a window layer in solar cells, in photovoltaic cells of Schottky diodes ${ }^{26,27}$ and as radiation filters. ${ }^{28}$

In this paper, thin films of CuSe have been prepared on indium doped tin oxide (ITO) coated glass substrates using electrodeposition technique. Deposited films were subjected to electrochemical studies, X-ray diffraction, scanning electron microscopy, optical analysis and spectroelectrochemical analysis.

\section{EXPERIMENTAL}

\subsection{Materials}

Reagents of copper sulphate, selenium dioxide, $\mathrm{H}_{2} \mathrm{SO}_{4}$ were analytical grade and ITO coated glass plate was obtained from Merck (India) Ltd. Chemicals were used as received without further purification. All the solutions were prepared by ultra-pure water.

\subsection{Methods}

UV-visible spectroscopy analysis was carried out by a UV-visible spectrophotometer Jasco V-530 between 300 and $1100 \mathrm{~nm}$, possessing a scanning speed of $400 \mathrm{~nm} \mathrm{~min}{ }^{-1}$. Cyclic voltammetric studies were done through computer controlled $\mathrm{CH}$ Instruments, and performed using a single-compartment cell with three electrodes, at room temperature. The surface morphology was studied by computer-controlled JEOL JSM-5600 LV. The computer controlled XRD system JEOL IDX 8030 was used to record the X-ray diffraction of samples. 


\section{RESULTS AND DISCUSSION}

\subsubsection{Growth of Copper Thin Film}

Figure 1 presented the growth of copper thin film on ITO surface, which was carried out in $5 \mathrm{ml}$ of $0.1 \mathrm{M} \mathrm{CuSO}_{4}$ in $0.1 \mathrm{M} \mathrm{H}_{2} \mathrm{SO}_{4}$ electrolyte, with potential range from -800 to $600 \mathrm{mV}$ at a scan rate of $50 \mathrm{mV} \mathrm{s}^{-1}$ through cyclic voltammetry. Copper thin film shows one well-defined oxidation peak around $125 \mathrm{mV}$ and reduction peak around $-450 \mathrm{mV}$ in the first cycle. After completion of six successive cycles, a contrasting red colour thin film was observed on the ITO surface.

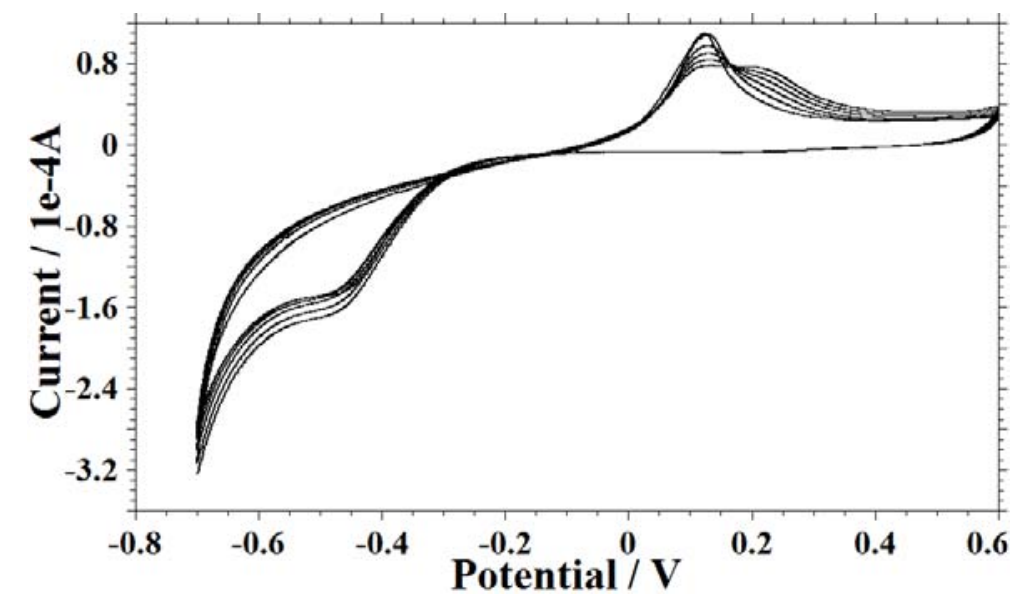

Figure 1: Cyclic voltammetric behaviour of copper thin film growth on ITO in $\mathrm{pH} 1.0$ scan rate at $50 \mathrm{mV} \mathrm{s}^{-1}$.

\subsubsection{Growth of Selenium Doped Copper Thin Film}

Figure 2 illustrates the result of preparing CuSe thin film on ITO surface studied in $5 \mathrm{ml}$ of $0.1 \mathrm{M} \mathrm{CuSO} 4$ in $0.1 \mathrm{M} \mathrm{H} 2 \mathrm{SO} 4$ and $2 \mathrm{ml}$ of $0.05 \mathrm{M} \mathrm{SeO} 2$ electrolyte, with potential range from -800 to $700 \mathrm{mV}$ at a scan rate of $50 \mathrm{mV} \mathrm{s}-1$ vs. $\mathrm{Ag} / \mathrm{AgCl}$ and through cyclic voltammetry. Voltammogram of thin film shows one oxidation and one reduction peak at $180 \mathrm{mV}$ and $-425 \mathrm{mV}$ for first cycle. After completion of the first cycle of voltammogram, five oxidation and one reduction peaks appear. Compared to voltammogram of copper thin film deposition, the additional number of oxidation peak indicates incorporation of selenium during deposition of thin films. As the number of cycle increased, the peak current of anodic peak and cathodic peak also increased. After completion of twelve cycles, a yellowish, red colour thin film formed on ITO surface. 


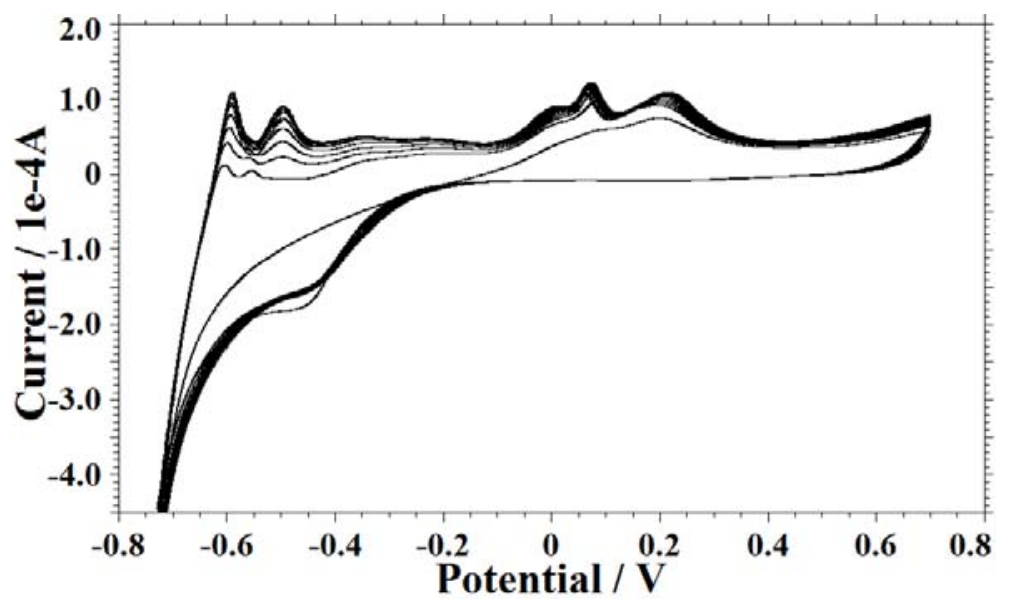

Figure 2: Cyclic voltammetric behaviour of CuSe thin film growth on ITO in pH 1.0: scan rate at $50 \mathrm{mV} \mathrm{s}^{-1}$.

\subsection{Effect of Scan Rate}

The CuSe thin film was washed well to remove copper, selenium and sulphate ions. The film was then subjected to cyclic voltammetry between -700 and 600 $\mathrm{mV}$ in $\mathrm{pH} 1.0$ aqueous supporting electrolyte solution. Figure 3 shows the cyclic voltammetric behaviour of $\mathrm{CuSe}$ thin film studied at different scan rates. As the scan rate was increased from 50 to $500 \mathrm{mV} \mathrm{s}-1$, both the anodic and cathodic peak current also increased linearly. This suggests good adherence and the electroactive nature of the formed thin film.

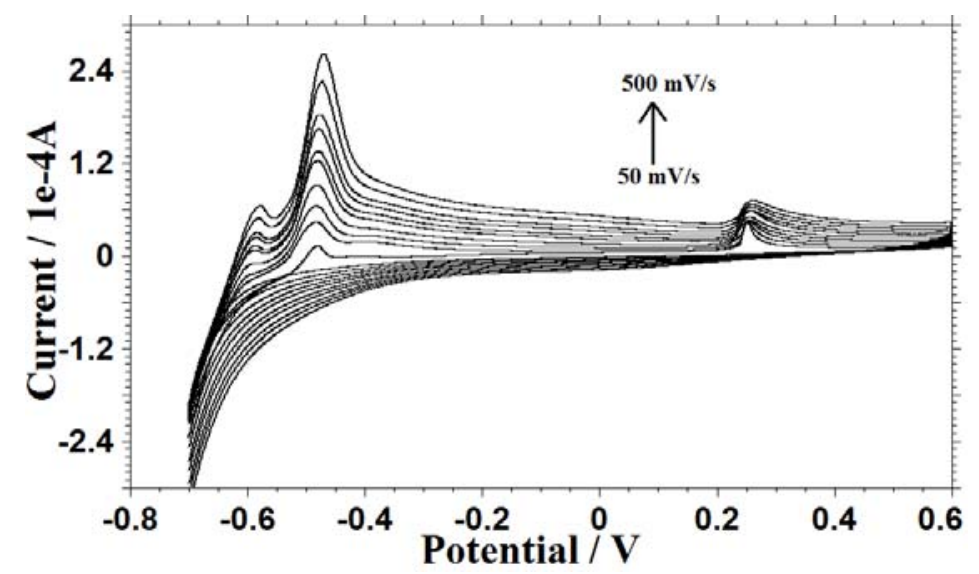

Figure 3: Cyclic voltammetric behaviour of $\mathrm{CuSe}$ thin film at different scan rate at 50$500 \mathrm{mV} \mathrm{s}^{-1}$. 


\subsection{Stability of CuSe Thin Film}

In order to examine the stability of the CuSe modified ITO plate, it was stored in an open atmosphere and the response current was monitored by employing cyclic voltammetry in $24 \mathrm{~h}$ interval to study the film stability. The potential cycling between $-1000 \mathrm{mV}$ and $1000 \mathrm{mV}$ at the scan rate of $50 \mathrm{mV} \mathrm{s}^{-1}$ was carried out and the changes were observed in the redox responses. The thin film exhibited no significant change in the redox behaviour during cycling up to 200 cycles in $\mathrm{pH}$ 1.0. Figure 4 illustrates the plot of peak current vs. time of modified electrode, where good stability is shown towards the atmospheric conditions, while responsibility of current is almost constant up to seventh day.

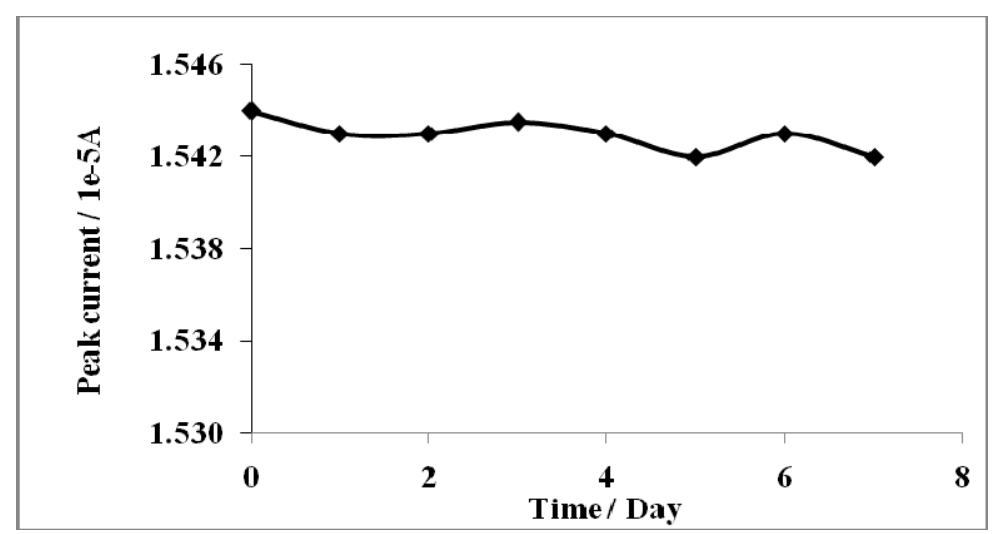

Figure 4: Plot of peak current vs. time.

\subsection{UV-Vis Spectroscopy and Optical Properties of CuSe Thin Films}

The UV-Vis photo spectra of CuSe thin films were recorded with respect to the bare substrate placed in the reference beam using double beam spectrophotometer in the range 300-1100 $\mathrm{nm}$. Figure 5 shows the absorbance and transmission data of the films versus wavelength. The spectrum shows a gradually increasing absorbance and a band at $500 \mathrm{~nm}$. Transmission throughout the visible region was good; cut-off transmission of $52 \%$ was observed at $300 \mathrm{~nm}$. 

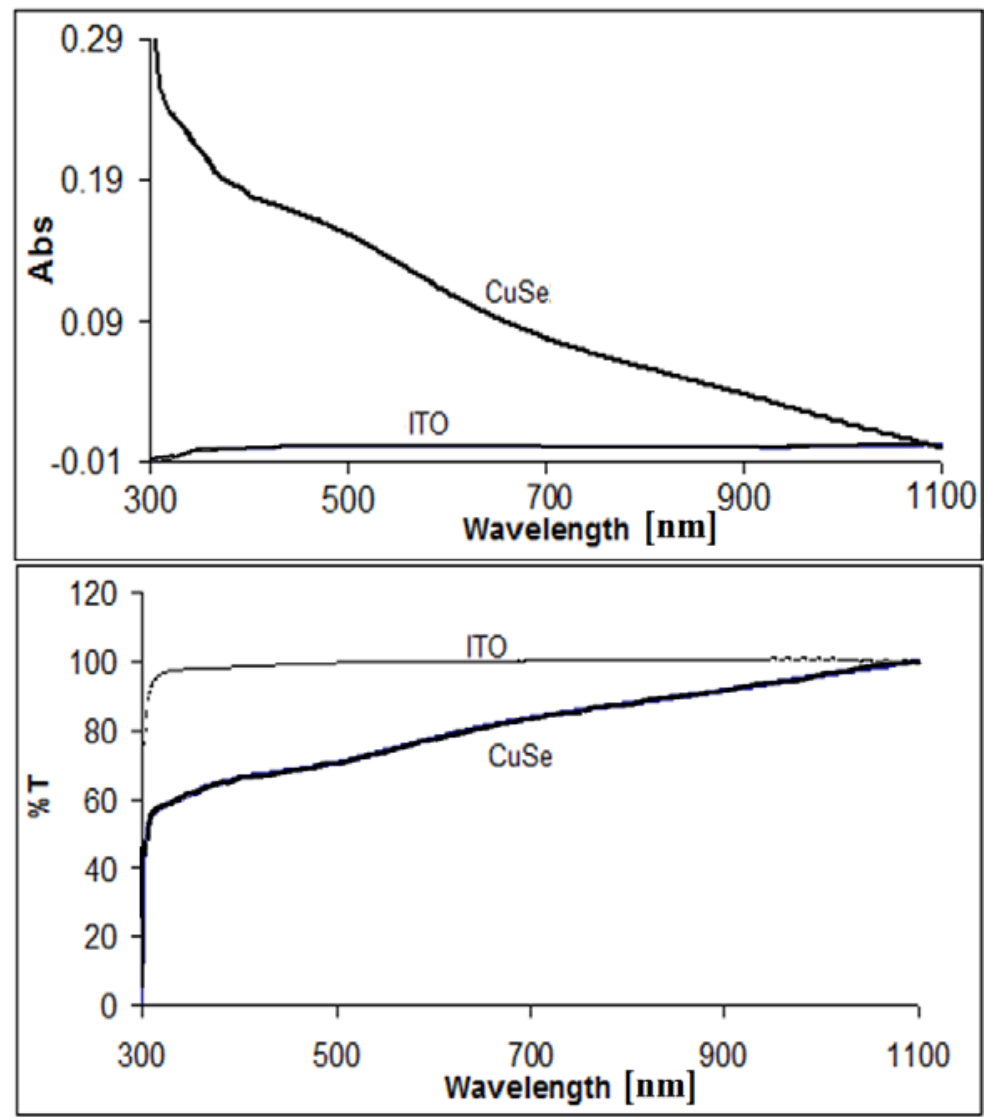

Figure 5: UV-Vis absorption and transmittance spectrum of CuSe thin film.

The band gap energy can be determined using the Tauc relation. It is a convenient way of studying the optical absorption spectrum of a material. According to the Tauc relation, the absorption coefficient $\alpha$ for direct band gap material is given by:

$$
\alpha h v=A(h v-E g)^{m}
$$

where A is the optical constant, $\alpha$ is the absorption coefficient, Eg is the optical band gap and $m$ is an index which assumes the values 1/2,3/2, 2 and 3 depending on the nature of electronic transition responsible for the reflection.

The band gap energy of thin film was determined by tauc plot. Tauc plot has the photon energy $(\mathrm{h} v)$ on the $\mathrm{X}$-axis and a quantity $(\alpha \mathrm{h} v)^{2}$ on the $\mathrm{Y}$-axis, and extrapolating the linear portion of the curve to the $\mathrm{X}$-axis yields the band gap energy of the material. Figure 6 shows the tauc plot of CuSe thin film coated with 
ITO plates in air medium. The band gap energy obtained for CuSe thin film is $1.78 \mathrm{eV}$ which is an improved value with the electrochemical deposition.

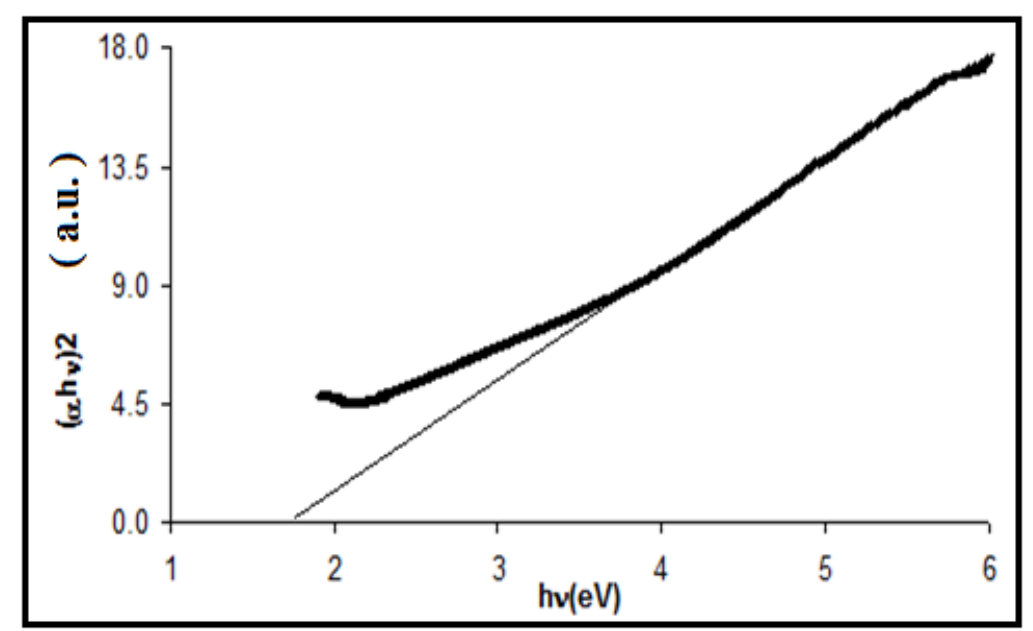

Figure 6: Tauc plot of CuSe thin film.

The sizes between $53.33 \mathrm{~nm}$ and $93.33 \mathrm{~nm}$, and the highly crystalline nature have a major impact on the lower band gap energy of the selenium incorporated copper nano thin film. The band gap value of copper doped tin oxide film is 3.55 $\mathrm{eV}$ as reported by Tripathy et al. ${ }^{29}$

\subsection{XRD Analysis of CuSe Thin Films}

X-ray diffraction patterns of CuSe thin films are shown in Figure 7. The diffraction peaks of spherical CuSe thin films are observed at the following $2 \theta$ values of angles: $5.484,13.620,42.896$ and 80.892 , corresponding to the lattice planes (l 11 1 $),\left(\begin{array}{lll}2 & 0 & 0\end{array}\right),\left(\begin{array}{lll}2 & 2 & 0\end{array}\right)$ and (4 20 ) respectively. The deposited film shows crystallinity and possesses cubic structure with lattice constant (a) of $80.892 \AA$. 


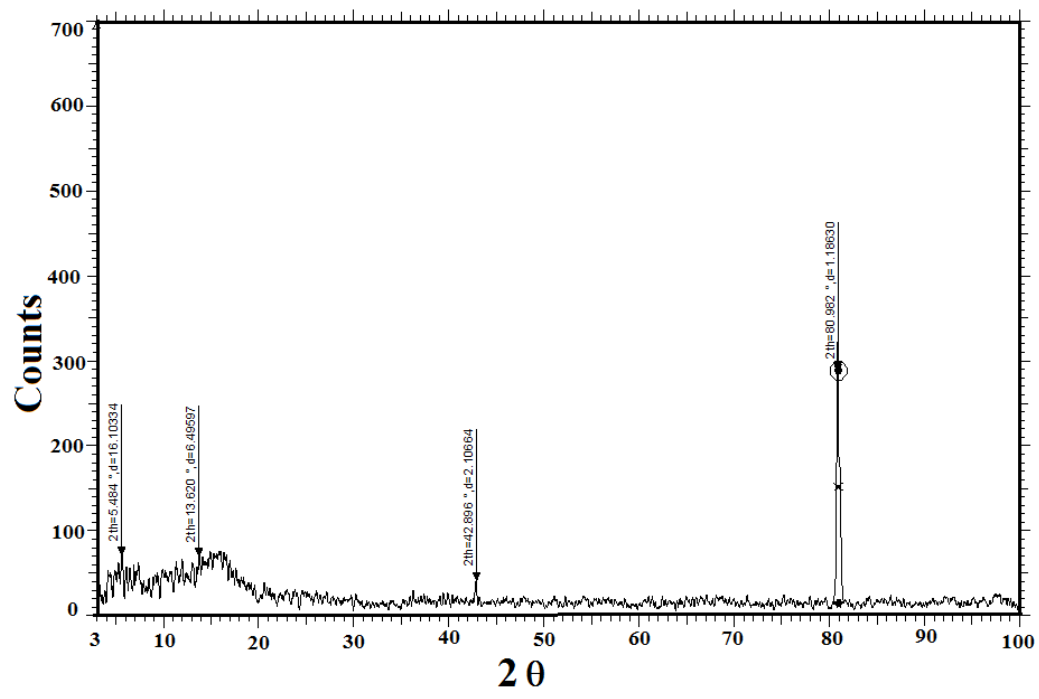

Figure 7: XRD behaviour of CuSe thin film.

\subsection{SEM Analysis of CuSe Thin Films}

The scanning electron microscopy image of CuSe thin films prepared at room temperature is shown in Figure 8. The image clearly demonstrates that the surface is well covered with CuSe thin films. The grains are much smaller in size, distributed evenly over the entire surface of the film and look like densely packed microcrystals. The average grain size continues decreasing with increasing amount of copper in the film composition. The larger the concentrations of the copper, the grains produced become smaller. For films with higher concentration of copper ions, the growth occurs with multiple nucleation centres, resulting in a lower grain size. On the other hand, for lower concentration of $\mathrm{Cu}$ ions, comparatively lower nucleation centres give higher grain size. The amount of feed material available in the reaction vessel is constant for a particular reaction. If the same material is divided into a larger number of nucleation centres, the grain would not grow larger but remain smaller. ${ }^{13}$ The grain shows uniform granular mixed texture-like structure. The sizes are found to be in the range between $53.33 \mathrm{~nm}$ and $93.33 \mathrm{~nm}$. 


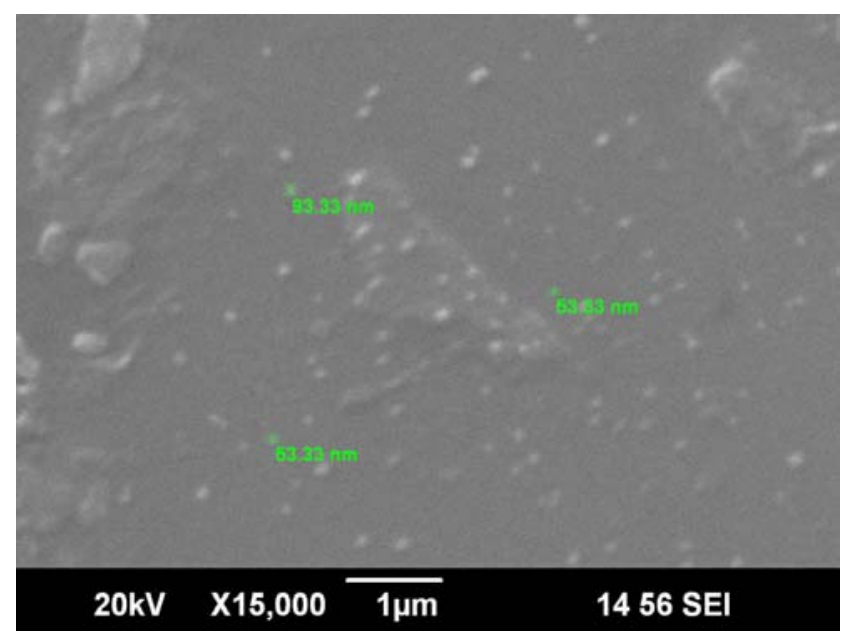

Figure 8: SEM behaviour of CuSe thin film.

\subsection{EDX Analysis of CuSe Thin Films}

The CuSe thin film composition was investigated using an EDX micro analytic unit attached with scanning electron microscopy and shown in Figure 9. The figure shows the presence of silica, indium, calcium, copper, selenium. The presence of emission lines in the investigated energy range indicates the formation of selenium incorporated copper thin films.

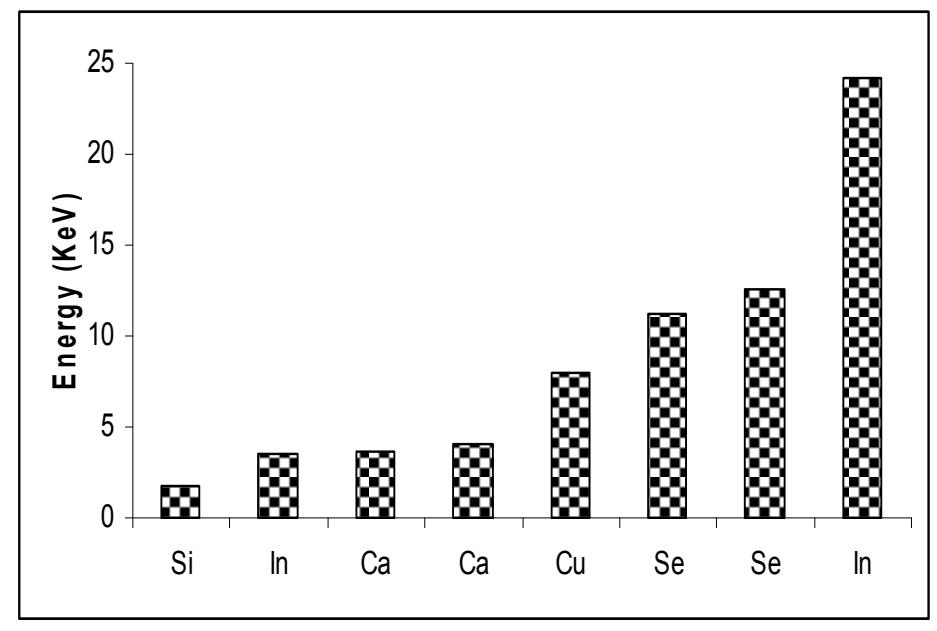

Figure 9: EDX behaviour of CuSe thin film. 


\subsection{Spectroelectrochemical Analysis of CuSe Thin Film}

Figure 10 shows the in-situ spectra of $\mathrm{CuSe}$ thin film at various applied potentials in $0.1 \mathrm{M} \mathrm{H}_{2} \mathrm{SO}_{4}$. Within the applied potential range, two absorption bands were observed at 300 and $900 \mathrm{~nm}$, while the absorbance increased linearly with the increasing potential from $-800 \mathrm{mV}$ to $800 \mathrm{mV}$. When the applied potentials were varied from $-800 \mathrm{mV}$ to $-100 \mathrm{mV}$, the thin film exhibited yellowish red colour. The band at $300 \mathrm{~nm}$ is associated with the $\pi-\pi^{*}$ transitions; one weaker band in visible region around $900 \mathrm{~nm}$ usually appeared during the doping process of thin films and was ascribed to formation of alloys subgap state. The thin film exhibited contrasting yellow colour within 0 and $800 \mathrm{mV}$ potential ranges.
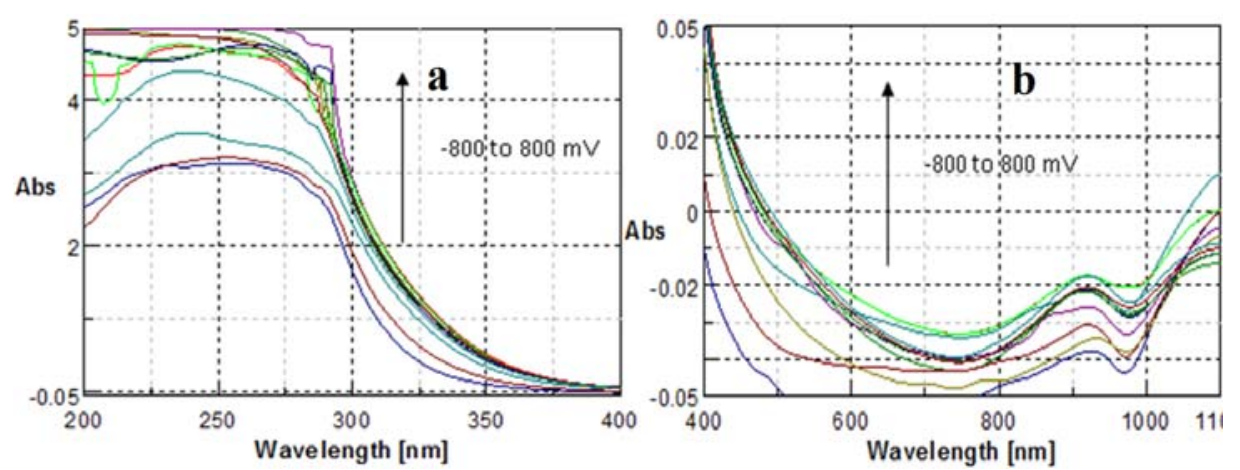

Figure 10: Spectroelectrochemical behaviour of CuSe thin film at various applied potential from $-800 \mathrm{mV}$ to $800 \mathrm{mV}$ at: (a) wavelength $200-400 \mathrm{~nm}$; and (b) wavelength $400-1100 \mathrm{~nm}$.

The importance in electrochromic devices based on thin film is due to their good optical contrast and stability. The CuSe thin film was stepped between its reduced and oxidised states. While the film was switched, the percentage transmittance at $\lambda_{\max }(300 \mathrm{~nm})$ was monitored as a function of time. The contrast is given as the difference between the reduced and oxidised states and reported as $\Delta \% \mathrm{~T}$. The results are presented in Table 1 . The controlled potential coulometry was employed to evaluate the coloration efficiency and response time. Figure 11 represents the electrochromic behaviour of $\mathrm{CuSe}$ (a) before oxidation; and (b) complete oxidation. 
Table 1: Electrochromic parameters of CuSe thin films.

\begin{tabular}{|c|c|c|}
\hline Parameters & Wavelength (nm) & Thin films \\
\hline $\begin{array}{l}\text { Coloration efficiency }\left(\mathrm{cm}^{2} / \mathrm{C}\right) \text {, } \\
\eta\end{array}$ & $\lambda_{300}$ & 620 \\
\hline \multirow{2}{*}{ Response time (s), $\tau$} & Colouring & 18 \\
\hline & Bleaching & 21 \\
\hline Optical contrast $(\Delta \% \mathrm{~T})$ & $\lambda_{300}$ & 81 \\
\hline
\end{tabular}
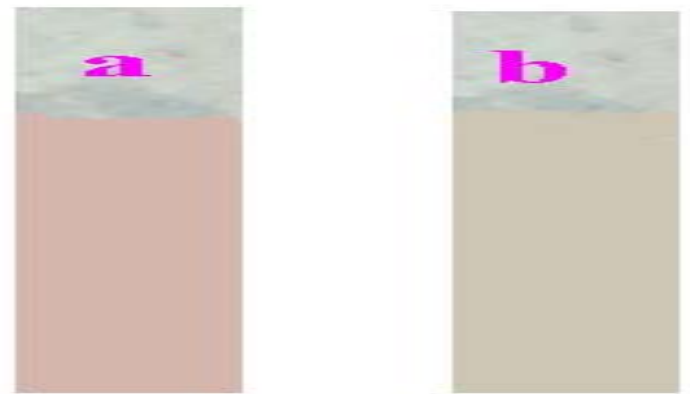

Figure 11: Electrochromic behaviour of CuSe (a) before oxidation (b) complete oxidation.

\section{CONCLUSION}

The cyclic voltammogram of $0.1 \mathrm{M}$ of $\mathrm{CuSO}_{4}$ and $0.05 \mathrm{M}$ selenium dioxide at potential range from -0.8 to $0.8 \mathrm{~V}$ vs. $\mathrm{Ag} / \mathrm{AgCl}$ in $\mathrm{pH} 1.0$ formed yellowish red colour CuSe thin film on ITO surface. Formed thin film possesses good adherent nature on electrode surface, good electroactivity and stability. The transmittance and absorption of thin films was analysed through UV-Vis spectra. An energy gap of $1.78 \mathrm{eV}$ is obtained for electrochemically synthesised $\mathrm{CuSe}$ thin films. X-ray diffraction patterns revealed that the deposited films possess cubic structure with lattice constant $\mathrm{a}=80.892 \AA$. Surface morphology of thin film shows uniform granular mixed texture like structure. The sizes of the grains are found to be in the range between $53.33 \mathrm{~nm}$ and $93.33 \mathrm{~nm}$. CuSe thin film exhibits dual colour chromic behaviour from contrasting yellowish red to contrasting yellow. The electrochromic device shows good optical contrast, coloration efficiency and response time. 


\section{ACKNOWLEDGEMENT}

The authors are extremely grateful to University Grants Commission (UGC) New Delhi, India for financial assistant and Department of Science and Technology (FAST TRACK and FIST) New Delhi, India, for the CHI Electrochemical workstation facilities at V.O.C College, Tuticorin-8. The research was supported by grants provided by Department of Science and Technology, New Delhi (Grant SR/FTP/CS-109/2007) and University Grants Commission, New Delhi (Grant F. No. 41-1108/2012 [SR]).

\section{REFERENCES}

1. Ramesh, K., Thanikaikarasan, S. \& Bharathi, B. (2014). Structural, morphological and optical properties of copper selenide thin films. Int. $J$. ChemTech Res., 6, 5408-5411.

2. Sakr, G. B. et al. (2010). Optical spectroscopy, optical conductivity, dielectric properties and new methods for determining the gap states of CuSe thin films. J. Alloy. Comp., 507(2), 557-562, DOI: 10.1016/j.jallcom.2010.08.022.

3. Murali, K. R. \& John Xavier, R. (2009). Characteristics of brush electroplated copper selenide thin films. Chalcogenide Lett., 6, 683-687.

4. Bhuse, V. M. et al. (2003). A simple, convenient, low temperature route to grow polycrystalline copper selenide thin films. Mater. Chem. Phys., 80(1), 82-88, DOI: 10.1016/S0254-0584(02)00306-1.

5. Khomane, A. S. (2012). Synthesis and characterization of chemically deposited $\mathrm{Cu}_{2}$-xSe thin films. Arch. Appl. Sci. Res., 4, 1857-1863.

6. Gosavi, S. R. et al. (2008). Physical, optical and electrical properties of copper selenide $(\mathrm{CuSe})$ thin films deposited by solution growth technique at room temperature. $J$. Alloy Comp., 448, 344-348, DOI: 10.1016/j.jallcom.2007.03.068.

7. Wang, Y. et al. (2014). Synthesis of ultrathin and thickness-controlled $\mathrm{Cu}_{2-\mathrm{x}} \mathrm{Se}$ nanosheets via cation exchange. J. Phys. Chem. Lett., 5, 36083613, DOI: $10.1021 /$ jz5019288.

8. Ivanauskas, R., Janickis, V. \& Jasulaitienè, V. (2013). Comparison characterization of copper selenide thin layers prepared on polyamide 6 films by sorption-diffusion method. Cent. Eur. J. Chem., 11, 636-643, DOI: $10.2478 / \mathrm{s} 11532-012-0200-5$.

9. Pengfei, H. \& Yali, C. (2012). Synthesis of rod and lath-shaped CuSe and tremella-shaped $\mathrm{Cu}_{2-\mathrm{x}} \mathrm{Se}$ nanostructures at room temperature, and their optical properties. J. Nanopart Res. 14, 703-710, DOI: 10.1007/s11051011-0703-6. 
10. Yakuphanoglu, F. \& Viswanathan, C. (2007). Electrical conductivity and single oscillator model properties of amorphous $\mathrm{CuSe}$ semiconductor thin film. J. Non-cryst. Solids, 353, 2934-2937, DOI: 10.1016/j.jnoncrysol.2007.06.055.

11. Peranantham, P. et al. (2007). The effect of annealing on vacuum evaporated copper selenide and indium telluride thin films. Mater. Charact., 58, 756-764.

12. Guanjun, X. et al. (2012). Solution synthesis of copper selenide nanocrystals and their electrical transport properties. CrystEngComm., 14, 2139-2144, DOI: 10.1039/C2CE06270D.

13. Bari, R. H. et al. (2009). Structural, optical and electrical properties of chemically deposited copper selenide films. Bull. Mater. Sci., 32, 37-42, DOI: $10.1007 / \mathrm{s} 12034-009-0006-z$.

14. Okereke, N. A. \& Ekpunobi, A. J. (2011). XRD and UV-VIS-IR studies of chemically-synthesized copper selenide thin films. Res. J. Chem. Sci., $1,64-70$.

15. Garcia, V. M., Nair, P. K. \& Nair, M. T. S. (1999). Copper selenide thin films by chemical bath deposition. J. Cryst. Grow., 203, 113-124, DOI: 10.1016/S0022-0248(99)00040-8.

16. Mamun, A., Firoz, S. H. \& Islam, A. B. M. O. (2004). Detection of crystal structure of chemically-deposited copper selenide thin films. Indian J. Phys., 78A(3), 377-379.

17. Mamun, A. Islam, A. B. M. O. \& Bhuiyan, A. H. (2005). Structural, electrical and optical properties of copper selenide thin films deposited by chemical bath deposition technique. J. Mater. Sci. Mater. Electr., 16, 263-268.

18. Durdu, B. G. et al. (2013). Investigation on sinc selenide and copper selenide thin films produced by chemical bath deposition. Acta Phys. Pol. $A, 124,41-45$.

19. Ezenwa, I. A., Okereke, N. A. \& Okoli, L. N. (2013). Optical properties of copper selenide thin film. Int. Res. J. Eng. Sci. Technol. Innov., 2(5), 82-87, DOI: 10.14303/irjesti.2013.042.

20. Colin, M. H. et al. (2011). Copper selenide nanocrystals for photothermal therapy. Nano Lett., 11, 2560-2566, DOI: 10.1021/nl201400z.

21. Kim, K. S. et al. (2003). Preparation of copper $(\mathrm{Cu})$ thin films by MOCVD and their conversion to copper selenide (CuSe) thin films through selenium vapor deposition. Bull. Korean Chem. Soc., 24, 647649.

22. Abdul Razak, M. F. S. \& Zainal, Z. (2007). Electrophoretic deposition and characterization of copper selenide thin films. Malaysian J. Anal. Sci., 11, 324-330. 
23. Thanikaikarasan, S. \& Mahalingam, T. (2012). Influence of solution $\mathrm{pH}$ in electrodeposited iron diselenide thin films. J. Alloys Comp., 511, 115122, DOI: 10.1016/j.jallcom.2011.09.003.

24. Okimura, H., Matsumae, T. \& Makabe, R. (1980). Electrical properties of $\mathrm{Cu}_{2-x} \mathrm{Se}$ thin films and their application for solar cells. Thin Solid Films, 71, 53-59, DOI: 10.1016/0040-6090(80)90183-2.

25. Bhuse, V. M. et al. (2003). A simple, convenient, low temperature route to grow polycrystalline copper selenide thin films. Mater. Chem. Phys., 80(1), 82-88, DOI: 10.1016/S0254-0584(02)00306-1.

26. Haram, S. K. \& Santhanam, K.S.V. (1995). Photoelectrochemical responses of orthorhombic and cubic copper selenides. J. Electroanal. Chem., 396, 63-68, DOI: 10.1016/0022-0728(95)04111-Z.

27. Brien, R. N. O. \& Santhanam, K. S. V. (1989). Laser interf erometry of electroless deposition of copper selenide. J. Electroanal. Chem. Interf. Electrochem., 260, 231-235, DOI: 10.1016/0022-0728(89)87115-3.

28. Garcia, V. M., Nair, P. K. \& Nair, M. T. S. (1999). Copper selenide thin films by chemical bath deposition. J. Cryst. Growth, 203, 113-124.

29. Tripathy, S. K., Nagarjun, B. \& Siva Jahnavy, V. (2013). Optical and structural characteristics of copper doped tin oxide thin film prepared by thermal evaporation method. Int. J. Eng. Innovative Technol., 3(1), 296300 . 